\title{
EL LEGADO DE VICENTE RIPOLLÉS PÉREZ (1867-1943) EN EL REAL COLEGIO SEMINARIO DE CORPUS CHRISTI DE VALENCIA: VISIÓN GLOBAL Y TRANSFERENCIA
}

\author{
THE LEGACY OF VICENTE RIPOLLÉS PÉREZ (1867-1943) \\ IN THE REAL COLEGIO SEMINARIO DE CORPUS CHRISTI IN VALENCIA: \\ A GLOBAL OVERVIEW AND TRANSFERENCE
}

Rosa Isusi Fagoaga

Universitat de València

Rosa.Isusi@uv.es

ORCID ID: https://orcid.org/0000-0003-3727-3865

\begin{abstract}
Resumen
Vicente Ripollés Pérez (1867-1943) fue unos de los maestros de capilla españoles más interesantes entre los siglos XIX y XX; destacó como compositor, director, musicólogo y por su liderazgo en el movimiento cecilianista. Llegó a ser nombrado canónigo de la Catedral de Valencia y fue maestro de capilla en las catedrales de Tortosa, Sevilla y el Real Colegio de Corpus Christi en Valencia. A esta última institución legó su archivo y biblioteca que han sido catalogados recientemente y que contienen más de ochocientos documentos. Ripollés merecería un estudio monográfico amplio que excede a las limitaciones de este texto. El objetivo de este trabajo es ofrecer una visión global y crítica sobre su legado, transferir conocimiento y facilitar con ello futuras investigaciones sobre este maestro pionero en la historiografía musical hispánica y sus contemporáneos.
\end{abstract}

\section{Palabras clave}

Patrimonio musical hispánico, historiografía musical, música valenciana, legados, epistolario, música sacra siglos XIX y XX, cecilianismo, música española, catalogación, transferencia de conocimiento.

\section{INTRODUCCIÓN}

"Si en esto algo soy y valgo es por el Patriarca" Vicente Ripollés Pérez

\begin{abstract}
Vicente Ripollés Pérez (1867-1943) was one of the most relevant Spanish chapel masters between the 19th and 20th centuries who stood out as a composer, conductor, musicologist and for his leadership in the Cecilianist movement. He became canon at Valencia cathedral and was a chapel master in the cathedrals of Tortosa, Seville and the Royal College of Corpus Christi in Valencia. He bequeathed to the latter institution his archive and library, which have been recently catalogued and contain more than eight hundred documents. Ripollés would deserve a comprehensive monographic study that exceeds the limitations of this article. The aim here is to offer a global and critical view of his legacy and to facilitate future research on this pioneering master of Hispanic music historiography and his contemporaries.
\end{abstract}

\section{Key words}

Hispanic musical heritage, music historiography, Valencian music, legacies, epistolary, sacred music 19th and 20th centuries, Cecilianism, Spanish music, cataloguing, transfer of knowledge.

Los legados de músicos resultan ser ricas fuentes documentales que permiten estudios interdisciplinares, enriquecen la investigación musicológica y ofrecen visiones culturales amplias. Las bibliotecas y composiciones de los músicos solían 
quedar en las instituciones para las cuales trabajaban o pasar a sus herederos. En el primero de los casos, la documentación ha pasado a formar parte de los archivos musicales institucionales, en mayor medida sacros, y en el segundo ha sido frecuente su disgregación, pérdida o destrucción. Sin embargo, desde el siglo pasado ha ido en aumento la toma de conciencia por parte de los propios músicos y de sus herederos de la importancia de sus legados para la investigación. En el caso de los músicos hispánicos entre los siglos XIX y XX, ámbito cronológico en el cual centramos este estudio, sobresalen los legados de varios músicos y musicólogos que se conservan en bibliotecas públicas y han sido catalogados. Este es el caso de los legados de Francisco Asenjo Barbieri conservado en la Biblioteca Nacional de España en Madrid, el de Felipe Pedrell en la Biblioteca de Catalunya en Barcelona y el de Eduardo López-Chávarri Marco en la Biblioteca Valenciana en Valencia. ${ }^{1}$ Otro caso similar es el de los archivos y bibliotecas a cargo de fundaciones, como el Archivo Manuel de Falla en Granada. En otras ocasiones, las instituciones religiosas han sido las que han recibido legados de músicos vinculados a ellas, como en el caso que nos ocupa.

Vicente Ripollés Pérez nació en Castelló de la Plana en 1867, se formó como violinista y tiple en la capilla parroquial de su ciudad, cursó la carrera eclesiástica en el Seminario de Tortosa y cimentó sus estudios de composición con Salvador Giner en Valencia. ${ }^{2}$ Posteriormente se convirtió en una de las personalidades musicales más interesantes de su época, desarrolló una fructífera labor como maestro de capilla en la Catedral de Tortosa (1893-95), el Real Colegio-Seminario de Corpus Christi de Valencia (1895-1902), Catedral de Sevilla (1903-09), maestro de canto coral de la Catedral Metropolitana de Valencia y profesor del Seminario de esa ciudad (1909-1927). A partir de este último año fue nombrado canónigo de la catedral de Valencia por el arzobispo debido a la gran consideración de la que gozaba y se dedicó fundamentalmente a la investigación musicológica hasta su fallecimiento en 1943.

Ripollés fue uno de los músicos más activos durante los congresos de música sagrada que se celebraron en Valladolid, Sevilla, Barcelona y Vitoria en las primeras décadas del siglo XX. Durante el Congreso Nacional de Música Sagrada que tuvo lugar en Barcelona en 1912 se fundó la Asociación Ceciliana Española y Ripollés fue presidente de esta hasta su disolución una década más tarde. Cabe añadir que fue miembro del Conse11 Valencià de Cultura y de la Sociedad Internacional de Musico-

\footnotetext{
${ }^{1}$ Emilio Casares, Francisco Asenjo Barbieri. Documentos sobre música española y epistolario (Legado Barbieri), 2 vols. (Madrid: Fundación Banco Exterior, 1988); Rafael Díaz Gómez y Vicente Galbis, eds., Eduardo López-Chávarri Marco: correspondencia (Valencia: Generalitat Valenciana, 1996).

2 José Ruiz de Lihory, "Ripollés (Vicente)", en La música en Valencia. Diccionario biográfico y crítico (Valencia: Doménech, 1903; edición facsímil, Valencia: Librerías París-Valencia, 1987), p. 389.
}

logía, con la que participó en los congresos de Basilea (Suiza) y Barcelona. ${ }^{3}$

La figura, obra musical e investigaciones de Vicente Ripollés han sido objeto de breves estudios en diferentes diccionarios, enciclopedias e historias de la música. ${ }^{4}$ También sus escritos musicológicos, su vinculación con el movimiento ceciliano y con la aplicación del Motu proprio en alguna de las instituciones y ciudades en las que trabajó han recibido atención. ${ }^{5}$ Recientemente su obra musical ha empezado a editarse para que pueda ser interpretada, conocida y valorada. ${ }^{6}$

Sin embargo, la figura, obra musical y legado de Ripollés todavía ofrecen un amplio campo de investigación que merece ser objeto de estudios monográficos. En este sentido, los objetivos de este trabajo son, por una parte, ofrecer una visión unitaria del legado de Vicente Ripollés y, por otra, presentar a la comunidad científica la base de datos en línea del catálogo con los fondos musicales del Real Colegio realizado hasta el momento. En esta base de datos se encuentran integradas las fichas catalográficas del legado Vicente Ripollés, a excepción de su correspondencia y documentación oficial que está pendiente de catalogación. No obstante, este trabajo aporta noticias inéditas sobre

3 Una biografía ampliada puede verse en Andrea Bombi, "Ripollés Pérez, Vicente", en Diccionario de la música valenciana, 2 vols., ed. Emilio Casares (Madrid: Iberautor Promociones Culturales, 2006), vol. 2, pp. 344-346; y Miguel López-Fernández, ed., Vicente Ripollés Pérez (1867-1943). Música en torno al Motu proprio para la catedral de Sevilla. Vol. 1. Misas. Estudio y edición, Monumentos de la Música Española, vol. 83 (Madrid: Consejo Superior de Investigaciones Científicas, Editorial CSIC; Barcelona: Institución Milá y Fontanals, 2017), pp. XxV-Xxviii.

4 José Climent, "Ripollés Pérez, Vicente", en Gran Enciclopedia de la Región Valenciana (Valencia: M. García Cantos, 1973), p. 56, y, del mismo autor, Historia de la música contemporánea valenciana (Valencia: Del Cénia al Segura, 1978); y Bombi, "Ripollés Pérez, Vicente”, pp. 344-346.

5 Ramón Robres y Vicente Castell, "Las obras de D. Vicente Ripollés Pérez, Presbítero", Boletín de la Sociedad Castellonense de Cultura, 19/2 (1944), pp. 132-138; Miguel Ángel Picó Pascual, "La aportación musicológica del canónigo Vicente Ripollés Pérez", Revista de Musicología, 27/1 (2004), pp. 287-292; Frederic Oriola Velló, Temps de músics $i$ capellans: l'influx del motu proprio Tra le sollicitudini a la diòcesi de València (1903-1936) (Valencia: Federació de Societats Musicals de la Comunitat Valenciana, 2011); Elena Micó Terol, Amancio Amorós Sirvent (1854-1925) y su proyección en la vida musical valenciana, tesis doctoral, Universitat de Barcelona, 2012; Miguel López-Fernández, La aplicación del Motu proprio sobre música sagrada de Pío X en la archidiócesis de Sevilla (1903-1910): gestión institucional y conflictos identitarios, tesis doctoral, Universidad de Granada, 2014; y Andrea Bombi, "En nombre del arte y de la Iglesia: Vicente Ripollés y la reforma ceciliana", en Pasados presentes. Tradiciones historiográficas en la musicología europea (1830-1930), ed. Andrea Bombi (Valencia: Universitat de València, 2015), pp. 169-201.

6 López-Fernández, ed., Vicente Ripollés Pérez (1867-1943). Está prevista la publicación de un segundo volumen en Monumentos de la Música Española. 
esta correspondencia y documentación oficial que se han podido consultar personalmente en el Real Colegio.

La base de datos con las fichas catalográficas de los fondos musicales del Real Colegio fue realizada por un equipo interdisciplinar de musicólogos y documentalistas, siguiendo la estructura para registro de datos bibliográficos MARC 21 (Machine-Readable Cataloging) mediante el soporte informático de Biblioteca Valenciana en el programa Absys y con la financiación de la Generalitat Valenciana. ${ }^{7}$ Es posible consultar la base de datos a través de la web de Biblioteca Valenciana, seleccionando el Catálogo colectivo del Patrimonio y dentro de este la opción de música, y a su vez dentro de esta última opción, la institución Real Colegio de Corpus Christi. ${ }^{8}$ Con el trabajo realizado ha sido posible contabilizar en el legado Vicente Ripollés en torno a ochocientos documentos. A través de esta base de datos, en cuya elaboración he participado, se pretende transferir el conocimiento generado y, con ello, facilitar a los investigadores e intérpretes futuros estudios y ediciones musicales sobre este maestro pionero en la historiografía musical hispánica y sus contemporáneos. De esta forma se atiende a lo que se considera la "tercera misión" de las universidades, es decir, la transferencia de conocimiento a los profesionales que puedan usarlo y explotarlo. ${ }^{9}$ En este sentido, y siguiendo los estudios pioneros sobre transferencia de conocimiento en Humanidades y Ciencias sociales en nuestro país, consideramos que

En todas las áreas científicas el objeto transferido es, principalmente, conocimiento, pero también muchos de los resultados de la investigación se pueden concretar en un producto o artefacto susceptible de ser protegido mediante alguno de los títulos de propiedad legalmente establecidos (patentes, variedades vegetales, modelos de utilidad, semiconductores) y mediante derechos de autor, en el caso de las bases de datos o los programas informáticos. ${ }^{10}$

\section{HISTORIA DEL LEGADO}

\subsection{Institución receptora y custodia de la donación}

El propio Ripollés donó en vida su legado musical a la institución de la que había sido maestro de capilla entre 1895 y 1902 y donde comenzó su labor de reforma de la música religio-

\footnotetext{
${ }^{7}$ Este equipo estuvo dirigido y coordinado por las musicólogas Greta Olson y Rosa Isusi Fagoaga, respectivamente. Además, estuvo integrado de forma sucesiva por los documentalistas Verónica Forment Conde, Vicente Castellano, Clara Costa y Álida Reig.

$8<$ http://bv.gva.es/cginetbv-bin/abnopacbvccp/O6143/IDcb11ca03/ NT1>.

${ }_{9}$ Elena Castro Martínez, Ignacio Fernández de Lucio y Felipe Criado, "La transferencia del conocimiento desde las Humanidades: posibilidades y características", Arbor. Ciencia, Pensamiento y Cultura, 732 (2008), pp. 619-636, p. 620.

${ }^{10}$ Castro et al., "La transferencia", p. 629.
}

sa. ${ }^{11}$ La donación se produjo en 1939, año en que finalizó la Guerra Civil, tal y como ha quedado constancia en las etiquetas adheridas con posterioridad a su fallecimiento en 1943 en las monografías que le pertenecieron; véase Figura. 1.

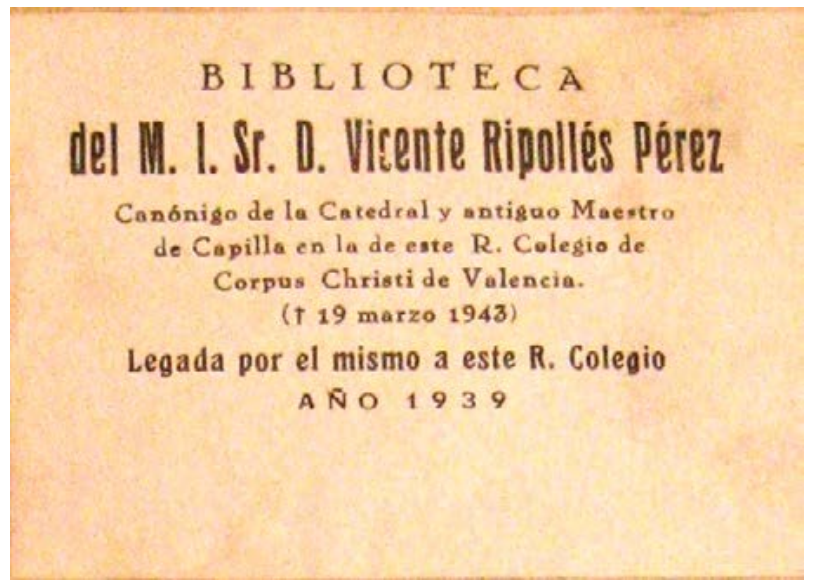

Figura 1. Etiqueta con la marca de propiedad de Vicente Ripollés Pérez. VAcp-Mus/VRP [monografías]. ${ }^{12}$

Ripollés probablemente se decidió a dejar la custodia de su legado al Real Colegio en vez de a la Catedral Metropolitana - de la que por aquel entonces era canónigo - después de ver cómo los muros del Real Colegio habían albergado temporalmente durante el conflicto los fondos de varios archivos y museos, entre ellos el de la Catedral de Segorbe (Castellón), Metropolitana de Valencia y parte de los fondos del Museo del Prado de Madrid, convirtiéndose en Centro de Recuperación del Patrimonio Artístico Nacional. Ripollés fue testigo de cómo el patrimonio del Real Colegio había quedado a salvo del probable saqueo que hubiera sufrido a comienzos de la guerra si no hubiera intervenido el rector de la Universidad de Valencia, José Puche, el decano de la Facultad de Medicina, Luis Urtubey, y el archivero Emilio Viñals. Ellos contuvieron y consiguieron convencer a la multitud congregada en el claustro del Real Colegio para que se retirara con la promesa de que la institución sería confiscada por la organización revolucionaria de estudiantes. Para evitar posibles excesos, las puertas del Colegio y de la Capilla

\footnotetext{
${ }^{11}$ Ripollés recogió el sentir de su época y plasmó su ideología sobre cómo tenía que ser la reforma adaptándola a la institución en la que trabajaba, el Real Colegio de Corpus Christi, en su Memoria sobre la reforma de la música religiosa en la Capilla del Real Colegio de Corpus Christi de Valencia (Madrid: Imprenta y Litografía de la Viuda e Hijos de Terceño, 1897), incorporando las normas sobre música litúrgica dictadas por la Santa Sede en 1884 y 1894, que culminaron años después en el Motu Proprio que promulgó el papa Pío X en 1903.

${ }_{12}$ Agradezco al rector del Real Colegio y al personal de su archivo la autorización para reproducir las imágenes.
} 
fueron rotuladas con la inscripción de «Confiscado por la Universidad Literaria. Este edificio es del pueblo. Respetadlo». La inscripción llevaba la firma del rector y el sello de la Universidad. Una guardia de milicianos y dos bedeles de la institución protegieron el edificio. ${ }^{13}$

El Real Colegio Seminario de Corpus Christi de Valencia es conocido como Colegio del Patriarca debido a que fue fundado por San Juan de Ribera (1532-1611), miembro de una poderosa familia de la nobleza sevillana. Tras su paso por la Universidad de Salamanca y el obispado de Badajoz, Juan de Ribera fue nombrado arzobispo, virrey, capitán general de Valencia y patriarca de Antioquía. Esta institución, inaugurada por los reyes Felipe III y Margarita de Austria en 1604 - a los que San Juan de Ribera había casado en Valencia - se dedicó a la adoración del Santísimo Sacramento y a seminario de sacerdotes. El patriarca San Juan de Ribera llevó a la práctica las doctrinas derivadas del Concilio de Trento (1545-1563) sobre las reformas del clero, de los estudios eclesiásticos y de la Eucaristía con la celebración de siete sínodos. También fundó varios colegios en localidades cercanas a Valencia, como los de Alboraya y Burjasot, erigió unas doscientas parroquias y patrocinó la instalación de más de ochenta y tres conventos de distintas órdenes religiosas. Por todo ello fue beatificado en 1796 y canonizado en $1960 .{ }^{14}$ Gracias a que el Patriarca fue un gran mecenas de las artes y a que el Real Colegio no sufrió la desamortización de Mendizábal en 1835 ni tampoco los saqueos durante la Guerra Civil (1936-39), la institución alberga el mayor patrimonio artístico, histórico y musical de la Comunidad Valenciana. ${ }^{15}$

San Juan de Ribera llevó a cabo un gran proyecto en el Real Colegio de difusión en Valencia del ideario de la Contrarreforma que quedó patente en las Constituciones y tuvo un gran interés en la música instituyendo un

nutrido coro que creó al dotar para la capilla musical del Colegio treinta capellanías primeras y quince segundas, con

${ }^{13}$ M. Martínez Tórtola, "Un Colegio junto al Estudio General. El Real Colegio de Corpus Christi y la Universitat de València", en Domus Speciosa. 400 años del Colegio del Patriarca (Valencia: Universitat de València, 2006), pp. 283-284.

${ }^{14}$ Ramón Robres, San Juan de Ribera, patriarca de Antioquía, arzobispo, virrey y capitán general de Valencia, 1532- 1611: humanismo y eclosión mística (Valencia: Edicep C.B., 2002).

${ }^{15}$ Véanse Fernando Benito Domenech, Pinturas y pintores en el Real Colegio de Corpus Christi (Valencia: Fewderico Doménech S.A., 1980); Fernando Andrés Robres, Inventario de los fondos notariales del Real Colegio Seminario de Corpus Christi (Valencia: Conselleria de Cultura, Educació i Ciència, 1990); Rosa Isusi-Fagoaga y Greta Olson, "Hacia un catálogo colectivo del patrimonio musical valenciano: el Real Colegio Seminario de Corpus Christi como primer paso", Boletín DM (Asociación Española de Documentación Musical, AEDOM), 11 (2007), pp. 92-97; y Greta Olson y Rosa Isusi-Fagoaga, "The Music Archive and Library at the Real Colegio Seminario de Corpus Christi (Valencia)", Fontes Artis Musicae, 55/3 (2008), pp. 512-518. voces escogidas para el canto, y establecer la Schola Cantorum con seis infantillos, niños de coro, que recibían allí enseñanza. Incluyó además una cobla de ministriles dirigida por Juan Aguilar, con seis tañedores de instrumentos: dos tiples, dos contrabajos, un tenor, y un contralto. Estos ministriles con sus chirimías: flauta, corneta y bajón, fabordones y varillas, añadían al canto en determinadas ocasiones efectos de majestuosa intensidad. Para el canto de órgano se construyeron dos órganos de tubería (...)

Finalmente, el arzobispo contrató como maestro de capilla a Juan Bautista Comes (1568-164), quien puso en marcha el grandioso proyecto $(\ldots){ }^{16}$

Es en esta magna institución y entre el rico patrimonio artístico que conserva donde se encuentra el legado del canónigo y musicólogo castellonense Vicente Ripollés Pérez. Al Real Colegio han llegado posteriormente otros importantes legados bibliográficos ${ }^{17} \mathrm{y}$ musicales que sí se han conservado en su mayoría de forma unitaria, como los de Enrique Domínguez Boví, ${ }^{18}$ José Romero López, Rafael Pallardó, José Esteve Larraga, José Manuel Fandos, Emilio Meseguer o el de las Hermanas Franciscanas de Gandía. ${ }^{19}$

\subsection{Ubicación, organización y catalogación}

Cuando el legado de Vicente Ripollés llegó al Real Colegio se disgregó; por una parte se agruparon las monografías y publicaciones periódicas, por otra las partituras, y aparte

${ }^{16}$ [San Juan de Ribera], Constituciones de la Capilla del Real Colegio y Seminario de Corpus Christi (Valencia, 1605), citadas y estudiadas por Daniel Benito Goërlich, "San Juan de Ribera, mecenas del arte", Studia philologica valentina, 15 (2013), p. 79. Para un conocimiento más profundo sobre la Capilla de Música y su actividad, véase Mireya Royo Conesa, La Capilla del Colegio del Patriarca: Vida musical y pervivencia de las danzas del Corpus de Juan Bautista Comes (16031706), tesis doctoral, Universidad de Oviedo, 2016.

${ }_{17}$ Daniel Benito Goërlich, "El legado Elías Tormo en el Real Colegio y Seminario de Corpus Christi de Valencia”, en Elías Tormo, apóstol de la historia del arte en España, dirigido por L. Arciniega (Valencia: Institució Alfons El Magnànim, 2016), p. 329. El valenciano Elías Tormo fue catedrático de Derecho, Teoría literaria e Historia del Arte en diferentes universidades españolas y llegó a ser Ministro de Instrucción Pública y Bellas Artes entre 1930 y 1931.

18 Rosa Isusi-Fagoaga, "El cantante Enrique Domínguez Boví, el teatro lírico y su colaboración con Manuel de Falla", en Delantera de Paraíso. Estudios en homenaje a Luis G. Iberni, ed. Celsa Alonso, Carmen Julia Gutiérrez y Javier Suárez-Pajares (Madrid: Universidad Complutense, 2009), pp. 187-199, y, de la misma autora, "El gremio musical en Valencia entre los siglos XIX y XX y el legado Enrique Domínguez Boví”, Cuadernos de música iberoamericana, 22 (2011), pp. 99-122.

${ }^{19}$ Rosa Isusi-Fagoaga, "La Música del Real Colegio Seminario de Corpus Christi (Patriarca): Primera visión global a la luz de su catalogación informática", Real Academia de Bellas Artes de San Carlos Valencia. Anuario (2014), pp. 43-56. 
quedaron los programas, la correspondencia, otra documentación y sus escritos. Las partituras llevaban la marca de propiedad escrita de forma autógrafa en bolígrafo azul "ex libris V. Ripollés", su firma en tinta negra o su cuño estampado; véanse Figuras 2, 3 y 4.

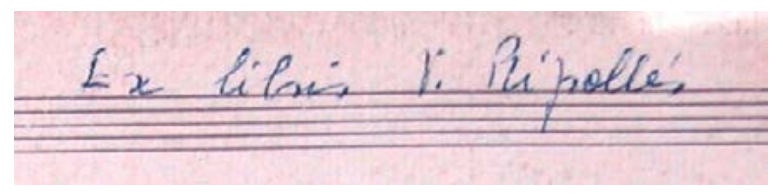

Figura 2. Marca de propiedad autógrafa "ex libris V. Ripollés" en las partituras.

VAcp-Mus/VRP [partituras]

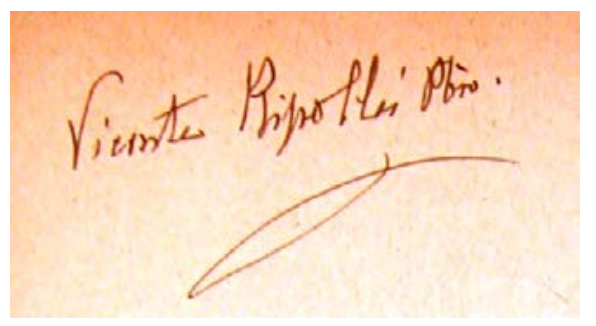

Figura 3. Firma autógrafa de Vicente Ripollés. VAcp-Mus/VRP.

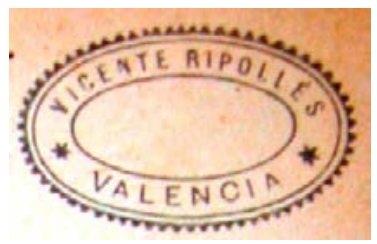

Figura 4. Cuño estampado con marca de propiedad de Vicente Ripollés en las partituras. VAcp-Mus/VRP [partituras]

Cuando se recibió el legado de Ripollés, el maestro de capilla del Real Colegio era Salvador Gea, que se había formado en la institución y ejerció de maestro y organista, a pesar de ser laico, entre los años convulsos de 1920 a 1944 . Entonces el archivo de música estaba ubicado en una dependencia junto a la Biblioteca de los Colegiales. Dado que en las etiquetas aparece mencionado el año de fallecimiento de Ripollés, podemos afirmar que estas se adhirieron a las monografías y publicaciones con posterioridad a 1943. Esto pudo ocurrir, bien durante el magisterio de Vicente García Julbe, entre 1944 y 1949, o en el de su sucesor Joaquín Piedra Miralles, entre 1950 y 1971. Este último fue quien comenzó la labor de catalogación del archivo de música y probablemente sería él quien ubicó las partituras con su marca de propiedad entre el fondo general de la capilla de música. Todavía se conserva el fichero manual que inició Joaquín Piedra. A muchas de estas partituras se les estampó posteriormente el cuño del Real Colegio Seminario de Corpus Christi.

Tras el fallecimiento del maestro Joaquín Piedra continuó su labor José Climent Barber, entonces organista de la Catedral de Valencia desde 1951 hasta su nombramiento como prefecto de música de la Catedral Metropolitana en 1981. Él publicó el inventario de los fondos musicales del Real Colegio centrado únicamente en las partituras, partes sueltas y libros de polifonía. ${ }^{20}$ Las monografías y publicaciones periódicas de la biblioteca personal de Ripollés habían permanecido sin catalogar probablemente debido a que se ubicaron en la Biblioteca del Colegio - y la mayoría de las partituras sí se catalogaron, ya que estaban insertadas entre el fondo general de la capilla de música. La correspondencia, otra documentación, escritos y programas permanecían inéditos y no se había tenido noticias sobre su existencia hasta fechas recientes.

El equipo interdisciplinar de musicólogos y documentalistas mencionado anteriormente comenzó en 2006 a organizar este legado musical, según el principio de procedencia, para su catalogación informática en línea al igual que el resto de fondos de esta institución privada. El resultado fue la agrupación de todos los documentos que pertenecieron a Ripollés y su inventariado y catalogación unitaria como un legado. ${ }^{21}$

\section{EL CORPUS DOCUMENTAL}

La biblioteca personal de Ripollés contiene poco más de un centenar de monografías, una veintena de publicaciones periódicas, unas trescientas cincuenta partituras y una docena de programas de conciertos.

\subsection{Monografías y publicaciones periódicas}

Entre las monografías y libros encontramos algunos publicados entre los siglos XV y XVIII, aunque la mayoría corresponden a finales del siglo XIX y principios del XX. Hay libros en varios idiomas además del castellano, como latín, italiano o francés, entre los que se encuentran los más interesantes que se publicaron en la época sobre música sacra, gregoriano y música española. Muchos de ellos son de singular relevancia por su antigüedad y por ser de difícil acceso en otras bibliotecas.

Se conserva algún libro manuscrito de gran formato y singular relevancia, como el tratado teórico de Pedro Rabassa Guía para los principiantes (fechado entre 1720 y 1767), 22 que debió

${ }^{20}$ José Climent, Fondos musicales de la Región Valenciana, II: Real Colegio-Seminario de Corpus Christi (Valencia: Institución Alfonso el Magnánimo, 1984).

${ }^{21}$ La sigla establecida por la comunidad científica para el Real Colegio es VAcp y la abreviatura que el equipo de catalogación creó para el legado de Vicente Ripollés Pérez fue VRP.

${ }^{22}$ Existe una edición facsímil a cargo de Francesc Bonastre, José Climent y Antonio Martín Moreno (Barcelona: Universitat Autònoma, 1990) y un estudio comparativo con los resúmenes manuscritos locali- 
pertenecer al archivo de la Catedral de Sevilla y que Ripollés compró en un anticuario de la ciudad durante su magisterio allí (1903-09). ${ }^{23}$ También se conserva con su marca de propiedad un resumen parcial del mismo con el título Reglas generales para la graduación [de las voces] realizado en 1758 en 18 páginas y que resulta semejante al manuscrito conservado en la Biblioteca de Catalunya (Bbc). ${ }^{24}$

A modo de ejemplo, podemos mencionar uno de los libros más antiguos de la biblioteca de Ripollés impreso en 1595. Se trata del Processionarium iuxta ritum ecclesiae dertusensis Valentiae que, debido a su antigüedad, se trasladó junto a los libros de la biblioteca personal de San Juan de Ribera - conocida como la biblioteca del Santo - tal y como se puede leer en la anotación manuscrita de la contraportada: "Este libro pasa de la Biblioteca del Colegio a la del Santo por ser del s. XVI. Valencia, 1 - marzo - 1962" [Firma ilegible]; véase Figura 5.

Entre algunos de los impresos del siglo XVII destacan los célebres tratados de Pietro Cerone De la musica theorica y pratica o Athanasius Kircher Musurgia universalis y El porqué de la música de Andrés Lorente en una edición de 1672. También hay alguno del siglo XVIII, como Le Rivoluzioni del teatro musicale italiano de Esteban de Arteaga en edición de 1785. Sin embargo, los más numerosos datan de finales del siglo XIX y principios del XX, entre los que destacan casi todos los trabajos que publicó Pedrell.

Entre las publicaciones periódicas que pertenecieron a Ripollés se encuentran no sólo las más destacadas del panorama español, sino también algunas del europeo. Se conservan una docena entre las publicadas en Madrid, Barcelona, Bilbao y Valencia, con varios ejemplares de Ilustración Musical Iberoamericana, La música religiosa en España, Música Sacro-Hispana, Revista Musical, Gaceta musical de Madrid, Crónica de la música, Revista y Gaceta musical, Revista montserratina, Vida cristiana, Tesoro sacro-musical, Biblioteca sacro-musical ${ }^{25}$ y Boletín de la Asociación Ceciliana Espa-

zados a cargo de Rosa Isusi-Fagoaga, Sevilla y la música de Pedro Rabassa. Los sonidos de la catedral y su contexto urbano en el siglo XVIII, 3 vols. (Sevilla: Junta de Andalucía. Consejería de Cultura y Deporte, 2012), vol. 1. pp. 497-503.

${ }^{23}$ Agradezco a Andrea Bombi la información sobre la compra de este manuscrito aparecida en la correspondencia enviada por Ripollés a Pedrell conservada en la Biblioteca de Catalunya.

${ }^{24}$ Pedro Rabassa, Reglas generales para la graduación, VAcp-Mus/ VRP-362 y Bbc, Ms. M 791/22.

${ }^{25}$ Se conservan ejemplares de la segunda época de esta revista que compró el editor Ildefonso Alier en 1911 y siguió editando desde Madrid. Esta revista fue creada en Valencia en 1890 por los editores y músicos Francisco Antich y Luis Tena y tuvo un destacado papel en la difusión de la música religiosa de compositores valencianos. Véase Rosa Isusi-Fagoaga, "La edición y recepción de música sacra en Valencia (ss. XVIII-XX): fuentes y publicaciones periódicas", en Imprenta y edición musical en España (siglos XVIII-XX), ed. Begoña Lolo y José Carlos Gosálvez (Madrid: Universidad Autónoma de Madrid, Ministerio de Economía y Competitividad, 2012), pp. 365-380.

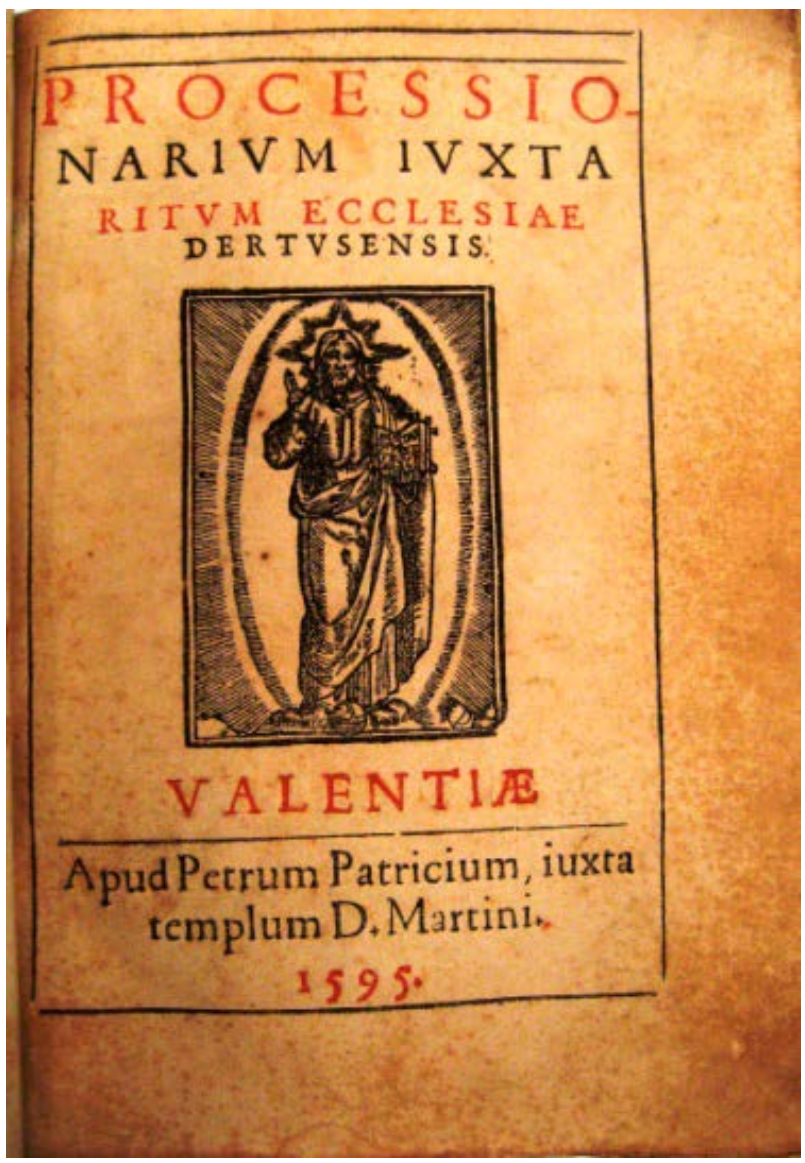

Figura 5. Processionarium iuxta ritum ecclesiae dertusensis (Valentiae: Petrum Patricium, 1595). VAcp-Mus/VRP-598.

ñola. También se encuentra la colección Lira Sacro-Hispana editada por Hilarión Eslava en 10 volúmenes a mediados del siglo XIX con las primeras ediciones en partitura de música de maestros del pasado.

Además, Ripollés estuvo suscrito a revistas italianas, que se conservan, publicadas en Roma y Turín como Santa Cecilia. Rivista mensuale di música sacra e litúrgica, Rassegna gregoriana per gli studi liturgici e pel canto sacro, Il Boletino Ceciliano: órgano ufficiale dell'Associazione Italiana S. Cecilia, y francesas editadas en París y Grenoble como Le Tribune de Saint-Gervais: bulletin mensuel de la Schola cantorum, Revue grégorien: études de chant sacré et de liturgie y Revue du chant grégorien. Otros ejemplares de revistas que se conservaban junto a los programas y correspondencia son El valencianet: revista infantil, Boletín oficial eclesiástico del obispado de Gerona, La Petite maîtrise: revue mensuelle de musique religieuse y Psalterium: Rassegna ceciliana mensile per la cultura delle scholae cantorum. 


\subsection{Partituras}

La mayoría de las partituras de la biblioteca personal de Ripollés son impresas. Casi todas están vinculadas al movimiento cecilianista de renovación de la música sacra católica que se extendió por toda Europa entre los siglos XIX y XX y el proceso de adaptación de las directrices papales del Motu proprio (1903). ${ }^{26}$

Entre el repertorio que reunió Ripollés se encuentran obras tanto de compositores valencianos y españoles del pasado - Juan Bautista Comes, Cristóbal de Morales o Francisco Guerrero - como de sus contemporáneos - Francisco Tito, José $\mathbf{M}^{\mathrm{a}}$ Úbeda, Juan Bautista Guzmán, José Esteve Larraga, Nemesio Otaño, José Sancho Marraco y Cándido Candi. Son abundantes las obras procedentes de Centroeuropa de compositores italianos, franceses y germanos, tanto del pasado - Palestrina, Marenzio, Lasso, A. Gabrielli y Haydn - como de la generación anterior a Ripollés - Gounod y Liszt - y de sus contemporáneos - Perosi, Bottazzo, Griesbacher, Gries y Mitterer. Con Ripollés se interpretó en el Real Colegio buena parte de este repertorio, tal y como relata José Ruiz de Lihory,

Entusiasta también de los grandes maestros, ha dado a conocer en su notable Capilla [del Real Colegio de Corpus Christi] la Misa en do menor de Schumann, la de SaintSaëns, la de Gloria de Liszt, de la Tebaldini, y otras producciones del género sagrado de indiscutible mérito, que se ejecutan como modelos en las escuelas de música de Milán, Ratisbona y París. ${ }^{27}$

A modo de ejemplo, podemos sacar a la luz la interesante partitura con la adaptación que hizo el maestro valenciano Francisco Javier Cabo sobre Las siete palabras de Joseph Haydn y que se estrenó en Valencia en 1821; véase Figura 6. La fuente documental era anónima y hemos podido atribuirla gracias a las siguientes noticias que aparecen manuscritas en las primeras páginas de un facticio con una recopilación de villancicos impresos que se cantaron en la Catedral de Valencia:

\footnotetext{
${ }^{26}$ El movimiento cecilianista se articuló en torno a la restauración del canto gregoriano, la recuperación de la polifonía del siglo XVI y la creación de un nuevo estilo de composición musical. Remitimos a los estudios específicos - en especial a los de María Nagore y $\mathbf{M}^{\mathrm{a}}$ Antonia Virgili- publicados en la Revista de Musicología, 27/1 (2004), que ofrece un monográfico con las Actas del Simposio Internacional 'El Motu Proprio de San Pío X y la música (1903-2003)', celebrado en Barcelona del 26 al 28 de noviembre de 2003. De Virgili véase, además, "La música religiosa en el s. XIX español", Revista Catalana de Musicologia, 2 (2004), pp. 181-202, y de Ángel Medina, "La música en el templo tras el motu proprio de San Pío X: una mirada desde los archivos de la Iglesia", Memoria ecclesiae, 31 (2008), pp. 21-44. Ese volumen está dedicado a Música y archivos de la Iglesia: Santoral hispano-mozárabe en las Diócesis de España, Actas del XXI Congreso de la Asociación celebrado en Santander (12 al 16 de septiembre de 2005).

${ }^{27}$ Ruiz de Lihory, "Ripollés", p. 389.
}

D. Franco. Xavier Cabo... compuso varias obras.... Las siete palabras que el Señor dixo en la cruz, puestas en música en italiano por D. José Hayden y acomodadas a la misma en idioma español por el antedicho D. Franco. Cabo; añadiendo por este la copla del Invitatorio y el Credo antes del terremoto; lo que se cantó por primera vez el Jueves Santo por la noche en la Iglesia Parroquial de S[a]n Pedro M[árti]r y S[a]n Nicolás Obispo en el año $1821 . .^{28}$

Ripollés también se interesó y conservó ejemplares de algunas obras escénicas profanas de moda en la época, como las óperas de Wagner, Saint-Säens o Gounod y también por otras españolas menos conocidas entonces como Celos aún del aire matan de Sebastián Durón o El compte Arnau de Pedrell. Algunas partituras impresas presentan dedicatorias autógrafas firmadas de los autores, como Juan Bautista Elústiza (VRP-184), Tomás Bellpuig (VRP-255), Nemesio Otaño (VRP-203) o Henry Collet; véase Figura 7.

Entre las partituras manuscritas encontramos gran parte de sus obras - muchas de ellas autógrafas firmadas - tanto de su período como maestro en el Real Colegio como del que pasó en Madrid y en la Catedral de Sevilla. Otras instituciones que conservan composiciones de Ripollés, sin intención de realizar un estudio exhaustivo, son las catedrales de Tortosa, Sevilla y Valencia, la Biblioteca de Catalunya y el Archivo Santuario de Loyola.

Cabe destacar que entre las partituras manuscritas con la marca de propiedad de Ripollés se encuentran obras autógrafas de maestros que trabajaron en Valencia en los siglos XVIII y XIX, entre ellas, por ejemplo, una Misa brevis a 12 voces de Francisco Cabo o Asustadas las sombras se esconden, baile para los seises de Salvador Giner. Además, se encuentran dos interesantes manuscritos del siglo XVIII con música para teclado, uno de ellos podría atribuirse a Juan Moreno y Polo, organista en la Catedral de Tortosa entre 1730 y 1776, pues en la primera hoja - aunque deteriorada - se lee " $[\mathrm{h}]$ echo en Tortosa 1774”. El otro contiene unas Recercadas para teclado anónimas seguidas de varias fugas, una de ellas de "Escarlati" [Domenico Scarlatti] que se corresponde con la última de sus Essercizi per gravicembalo (Londres, 1738).

En las monografías, publicaciones periódicas y partituras encontramos casi una veintena de cuños y sellos de editores, comercios y almacenes de música tanto de la ciudad de Valencia, como de otras de España y de otros países, como Francia, que nos aportan información sobre dónde se adquirieron los documentos; véase Tabla 1.

${ }^{28}$ VAcp-Mus/ BM-FA-11, Colección de letras de los villancicos que se cantaron en la noche de Navidad en la Santa Metropolitana Iglesia de Valencia en los años desde 1740 hasta 1814 inclusive en que se dio fin a dicha solemnidad. Probablemente estas anotaciones manuscritas pudo haberlas hecho el entonces maestro de capilla catedralicia Juan Vicente Cuevas, último de los maestros reseñados en el documento. 


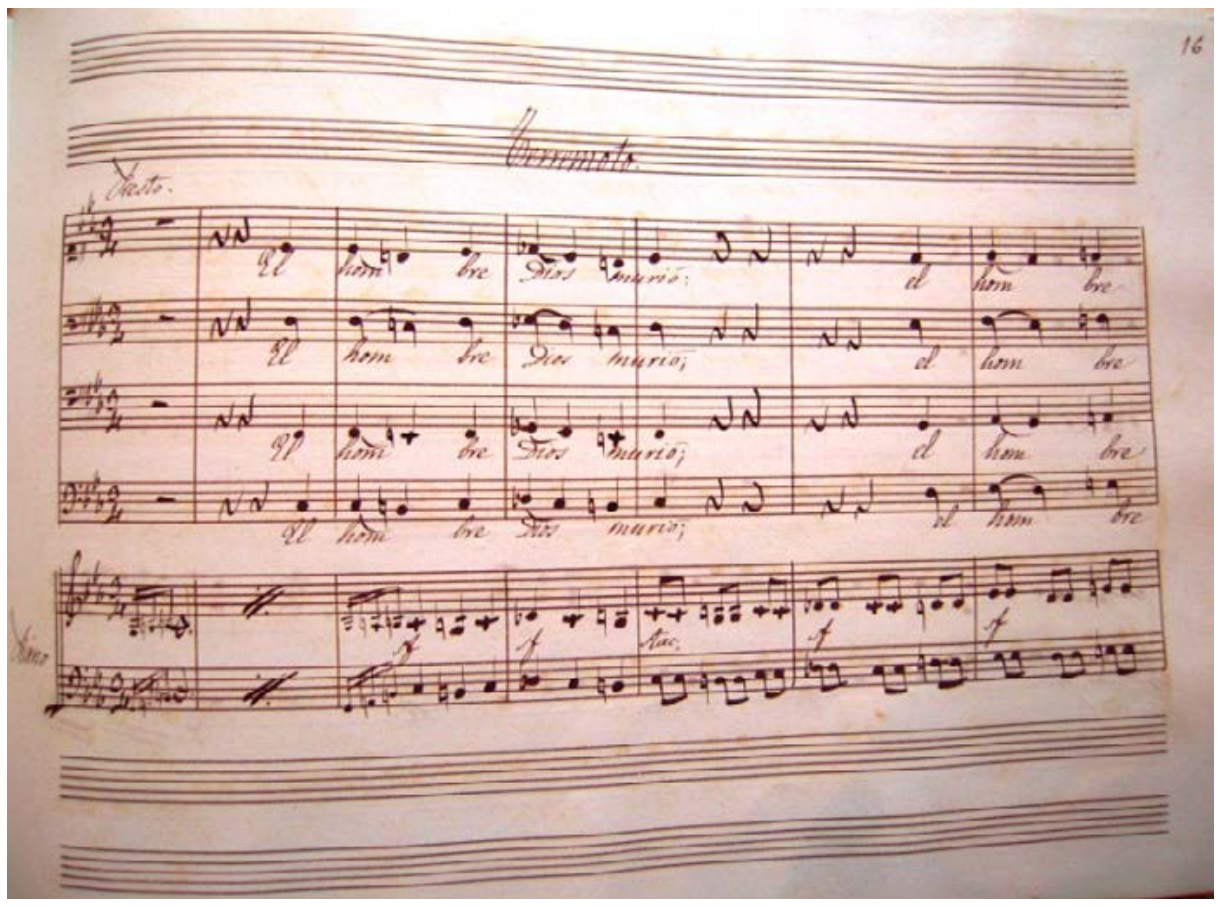

Figura 6. Francisco Javier Cabo / Joseph Haydn, [Las siete palabras], ms. [entre 1840 y 1893]. Fragmento de la sección del terremoto. VAcp-Mus/VRP-497.

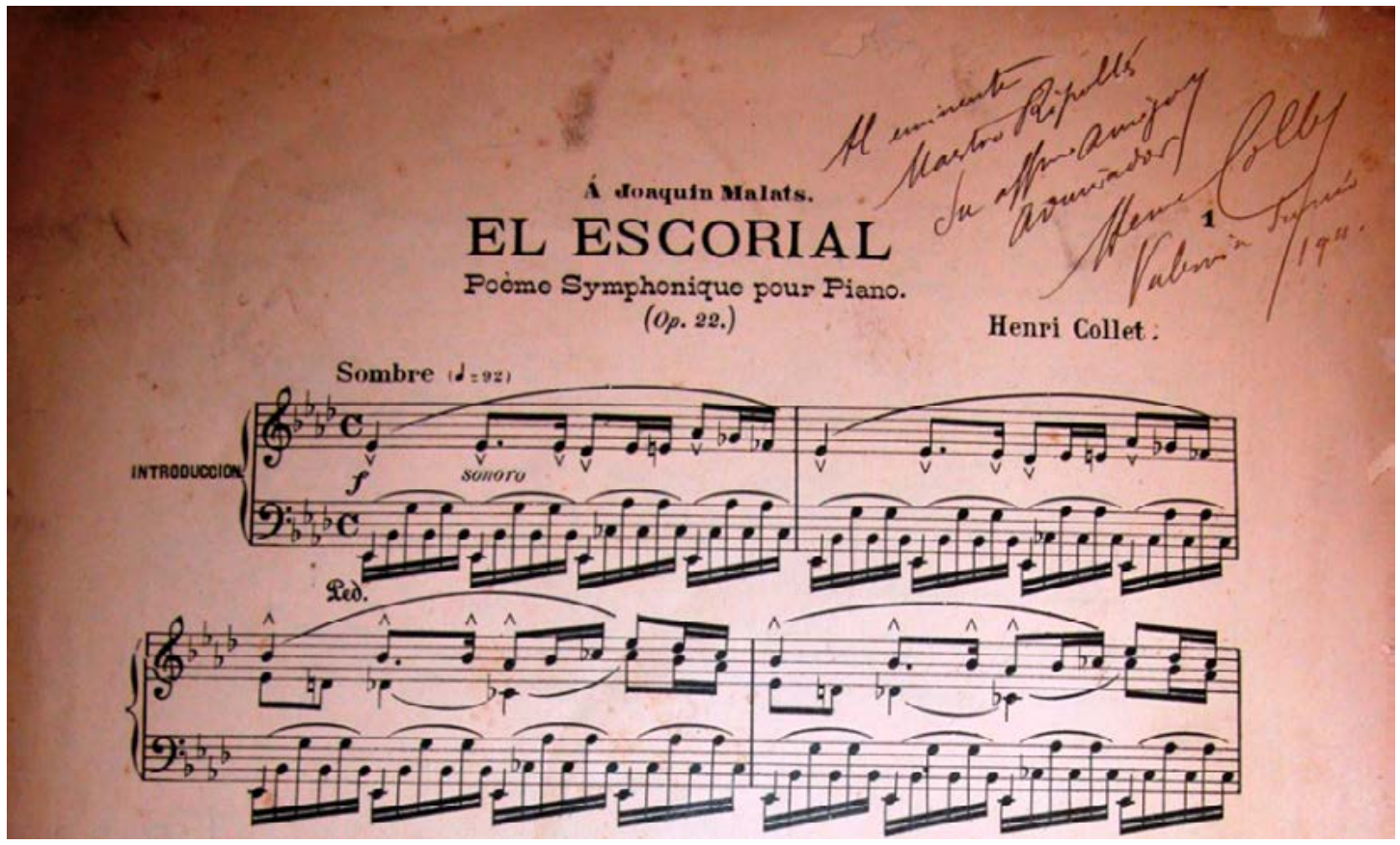

Figura 7. Dedicatoria de Henry Collet a Ripollés firmada en Valencia en 1911. VAcp-Mus/VRP-283. 


\begin{tabular}{|c|c|c|c|c|}
\hline Persona & Editorial/Comercio & Dirección & Lugar & Fecha \\
\hline $\begin{array}{l}\text { Antich, [Francisco] y } \\
\text { Tena, [Luis] }\end{array}$ & $\begin{array}{l}\text { Comercio de música - } \\
\text { Sucesores de S. Prósper }\end{array}$ & San Vicente, 99 & Valencia & 27 set. [18]95 \\
\hline Dotesio, Louis E. & $\begin{array}{l}\text { Almacén de música y } \\
\text { pianos }\end{array}$ & María Muñoz, 34 & Bilbao-Santander & \\
\hline Haas, Valentín de & $\begin{array}{l}\text { Pianos, instrumentos y } \\
\text { música }\end{array}$ & Rambla estudios, 11 & Barcelona & \\
\hline Heugel \& Cie. & Au Ménestrel & 2 bis Rue Viviene & [París] & \\
\hline $\begin{array}{l}\text { Márquez y Echeandía, } \\
\text { Luis }\end{array}$ & Encuadernador & Cánovas del Castillo, 7 y 9 & Sevilla & \\
\hline Prósper, Salvador & Comercio de música & San Vicente, 89 & Valencia & $2-$ jul. $[18] 81$ \\
\hline Pujol, Juan Bautista & $\begin{array}{l}\text { Universo musical, antes } \\
\text { Juan Bta. Pujol y Cía. }\end{array}$ & Puerta del Ángel, 1-3 & Barcelona & \\
\hline Romero & $\begin{array}{l}\text { Almacén, Música, Pianos, } \\
\text { Órganos }\end{array}$ & Preciados, 1 & Madrid & \\
\hline Rufin, R. & & 830.955 & Madrid & \\
\hline Saoc [¿] del Valle, Carlos & Pianos y música & Peligros, 9 & Madrid & \\
\hline Sánchez Laviña, carmelo & $\begin{array}{l}\text { Almacén de música e } \\
\text { instrumentos }\end{array}$ & Bajada de San Francisco, 29 & Valencia & 28 mayo $[18] 87$ \\
\hline Serrano, Eduardo & Almacén de música & Zaragoza, 29 & Valencia & \\
\hline \multirow[t]{4}{*}{ Tena, Luis } & $\begin{array}{l}\text { Sucesor de Antich y Tena } \\
\text { - Música e instrumentos } \\
\text { de todas clases }\end{array}$ & San Vicente, 99 & Valencia & \\
\hline & Iberia musical & Canuda, 45 & Barcelona & \\
\hline & & $\begin{array}{l}21, \text { R. des Posses } \\
\text { Montmartre }\end{array}$ & París & \\
\hline & Timbre Royal Seine & & [París] & \\
\hline
\end{tabular}

Tabla 1. Cuños de editoriales y comercios de música en el legado de Vicente Ripollés Pérez.

Fuente: Elaboración propia a partir del legado VRP en VAcp.

\subsection{Programas de conciertos}

Entre los programas de conciertos que conservó Ripollés se encuentran los que conmemoraron el tercer centenario de la muerte de San Juan de Ribera con la relación de composiciones que se interpretaron en el Real Colegio en julio de 1911, otro de la Sociedad Filarmónica de Valencia en 1916, varios de la Asociación de Música de Cámara de Barcelona en marzo de 1921, del Orfeó Català entre febrero de 1921 y abril de 1922 (alguno le fue enviado a Ripollés junto a una carta), de la Association Grégorianiste et Cécilianiste en Espagne de Gregori $\mathrm{M}^{\mathrm{a}}$ Sunyol y de la Semana Santa en la Catedral de Toledo en 1925.

\subsection{Epistolario}

El epistolario, la documentación profesional de carácter oficial y los borradores de los escritos musicológicos que poste- riormente publicó Vicente Ripollés permanecieron en otra dependencia fuera del archivo de música y se dieron a conocer en 2007 por Daniel Benito Göerlich, conservador del patrimonio artístico del Real Colegio y profesor de Historia del Arte de la Universitat de València. Esta documentación fue ordenada e inventariada por el organista y responsable del archivo musical del Real Colegio, Vicente Ferrer Granell. Está previsto proceder a su catalogación informática - y si es posible a su ediciónpara que en el futuro pueda ser consultada por los investigadores.

En el Real Colegio se conserva parte de la correspondencia que Ripollés mantuvo con sus contemporáneos músicos, en especial la que otros músicos le enviaron. ${ }^{29}$ Entre estas cartas

29 Probablemente las cartas que él envió deben conservarse entre los legados de los destinatarios. Se desconoce dónde se encuentran las car- 


\begin{tabular}{|c|c|c|c|c|}
\hline Persona & Datos biográficos & $\mathbf{N}^{0}$ cartas/tarjetas & Lugares & Fechas \\
\hline Anglés, Higini & $\begin{array}{l}\text { Biblioteca de Cataluña y Dir. } \\
\text { Instituto Español de } \\
\text { Musicología }\end{array}$ & 47 с у $27 \mathrm{t}$ & $\begin{array}{l}\text { Barcelona, Madrid, } \\
\text { Friburgo, Gotinga, } \\
\text { Gandía }\end{array}$ & $\begin{array}{l}\text { Entre 27.II.1919 y } 18 . \\
\text { III.1936 }\end{array}$ \\
\hline $\begin{array}{l}\text { Arabaolaza, } \\
\text { Gaspar de }\end{array}$ & MC Catedral de Zamora & $1 \mathrm{c}$ & [Zamora] & 4.IV.1923 \\
\hline Benito, Manuel de & & $3 \mathrm{c}$ & Comillas (Santander) & 25.IX.1911 y 16.II.1912 \\
\hline [i] Benjamín & $\begin{array}{l}\text { Pontificio Colegio Español de } \\
\text { S. José }\end{array}$ & $1 \mathrm{c}$ & Roma (Italia) & 13.II.1914 \\
\hline Bordés, José & Presbítero & $1 \mathrm{c}$ & Forcall (Castellón) & 9.VIII.1915 \\
\hline $\begin{array}{l}\text { Breva, Manuel } \\
\text { Andrés }\end{array}$ & & $1 \mathrm{c}$ & Castellón & VI.1917 \\
\hline Castrillo, Gonzalo & $\begin{array}{l}\text { Comisión Música Religiosa } \\
\text { Diócesis Palencia }\end{array}$ & $1 \mathrm{c}$ & [Palencia] & 14.XI.1918 \\
\hline Collet, H[enry] & & $1 \mathrm{c}$ & Francia & III.1908 \\
\hline $\begin{array}{l}\text { Guzmán, [Juan } \\
\text { Bautista] }\end{array}$ & $\begin{array}{l}\text { MC Catedral de Valencia y } \\
\text { monje Abadía Montserrat }\end{array}$ & $1 \mathrm{c}$ & Montserrat (Barcelona) & 24.VI.1908 \\
\hline $\begin{array}{l}\text { Martínez, } \\
\text { Francisco } \\
\end{array}$ & Organista y organero & $1 \mathrm{c}$ & Covarrubias (Burgos) & 17.X.1908 \\
\hline $\begin{array}{l}\text { Martínez Galbis, } \\
\text { José }\end{array}$ & Presbítero & $1 \mathrm{c}$ & Onteniente (Valencia) & 19.X.1908 \\
\hline Mérian, M. & $\begin{array}{l}\text { Secretario de la Sociedad } \\
\text { Internacional de Musicología }\end{array}$ & $1 \mathrm{c}$ & & II.1928 \\
\hline Müller, Hermann & Profesor de Teología & $2 \mathrm{c}$ & $\begin{array}{l}\text { Paderborn, Westfalen } \\
\text { (Alemania) }\end{array}$ & 19.XI.1922 \\
\hline Llopis, Domingo & & $1 \mathrm{c}$ & Castellón & 9.V.1928 \\
\hline López, Juan B. & & $1 \mathrm{c}$ & Villarreal (Castellón) & 25.I.1936 \\
\hline $\begin{array}{l}\text { Olmeda, } \\
\text { F[ederico] }\end{array}$ & & $2 \mathrm{c}$ & Madrid & 1.II.1908 y 11.III.1908 \\
\hline Otaño, Nemesio & & 41 c y $15 \mathrm{t}$ & $\begin{array}{l}\text { Oña (Burgos), Comillas } \\
\text { (Santander), Alzola } \\
\text { (Guipúzcoa) Palencia, } \\
\text { Manresa y Barcelona }\end{array}$ & $\begin{array}{l}\text { Entre 10.IX.1909 y } \\
\text { 19.XII.1921 }\end{array}$ \\
\hline $\begin{array}{l}\text { Pastor, Juan } \\
\text { Bautista }\end{array}$ & \begin{tabular}{|l} 
Maestro de coro de la \\
Catedral de Valencia
\end{tabular} & $1 \mathrm{c}$ & Valencia & 11.III.1912 \\
\hline Pedrell, Felipe & Compositor y musicólogo & $5 \mathrm{c}$ & Madrid & $\begin{array}{l}\text { Entre 12.XI.1903 y } \\
\text { 23.II.1904 }\end{array}$ \\
\hline $\begin{array}{l}\text { Pérez de Viñaspre, } \\
\text { Francisco }\end{array}$ & $\begin{array}{l}\text { MC y organista Catedral de } \\
\text { Burgos }\end{array}$ & $21 \mathrm{c}$ & $\begin{array}{l}\text { Burgos, San Sebastián, } \\
\text { Oñate (Guipúzcoa), } \\
\text { Logroño y Vitoria }\end{array}$ & $\begin{array}{l}\text { Entre 1.VII.1912 y } \\
\text { 29.XII.1931 }\end{array}$ \\
\hline Romeu, Lluís & \begin{tabular}{|l|}
$\begin{array}{l}\text { MC Catedral de Vic } \\
\text { (Barcelona) }\end{array}$ \\
\end{tabular} & $9 \mathrm{c}$ & Vic (Barcelona) & $\begin{array}{l}\text { Entre 10.VIII.1921 y } \\
25 . \text { V.1923 }\end{array}$ \\
\hline [Ripollés], Paco & Sobrino de VRP & $3 \mathrm{c}$ & Toledo y Madrid & $\begin{array}{l}\text { Entre } 22 . X .1924 \text { y } 15 . \\
\text { XII.1925 }\end{array}$ \\
\hline Sablayrolles, Maur & $\begin{array}{l}\text { Monje en Abbaye St. Benoît } \\
\text { d'En Calcat }\end{array}$ & $1 \mathrm{c}$ & Dourgne, Tarn (Francia) & 29.XII.1920 \\
\hline
\end{tabular}




\begin{tabular}{|c|c|c|c|c|}
\hline Sala, Jaime & & $1 \mathrm{c}$ & Santo Espíritu del Monte & 21.IX.1912 \\
\hline Santi, Angelo de & $\begin{array}{l}\text { Assoziacione italiana - Santa } \\
\text { Cecilia }\end{array}$ & $1 \mathrm{c}$ & Roma & 2.V.1913 \\
\hline Sojo, Francisco C. & & $1 \mathrm{c}$ & Plasencia (Cáceres) & 26.X.1908 \\
\hline Subirá, José & Musicólogo & $1 \mathrm{t}$ & Madrid & 20.IV.1934 \\
\hline Suñol, Gregorio & & $4 \mathrm{c}$ & Montserrat (Barcelona) & $\begin{array}{l}\text { Entre 5.II.1923 y } 24 . \\
\text { IX.1923 }\end{array}$ \\
\hline Villalba, Luis & & $10 \mathrm{c}$ & El Escorial (Madrid) & $\begin{array}{l}\text { Entre 17.X.1908 y } \\
\text { 26.I.1926 }\end{array}$ \\
\hline Villabra, Jesús & & $1 \mathrm{c}$ & Vitoria & 28.VII.1930 \\
\hline Ximeno & & $1 \mathrm{c}$ & [Valencia] & $\dot{8}$ \\
\hline Zafra, D. J. M. de & & $1 \mathrm{t}$ & Bayreuth (Alemania) & 21.VIII.1908 \\
\hline$i$ & $\begin{array}{l}\text { Alcaldía Constitucional de } \\
\text { Castellón }\end{array}$ & $1 \mathrm{c}$ & Castellón & 13.XII.1921 \\
\hline$\dot{q}$ & $\begin{array}{l}\text { Asociación germánica de } \\
\text { Santa Cecilia }\end{array}$ & $2 \mathrm{c}$ & [Alemania] & $i$ \\
\hline$\dot{i}$ & $\begin{array}{l}\text { Associazione italiana Santa } \\
\text { Cecilia }\end{array}$ & $1 \mathrm{c}$ & Turín (Italia) & 27.VIII.1920 \\
\hline$\dot{i}$ & $\begin{array}{l}\text { Sociedad Internacional de } \\
\text { Musicología }\end{array}$ & $1 \mathrm{c}$ & Basilea (Suiza) & 15.VI.1934 \\
\hline
\end{tabular}

Tabla 2. Correspondencia dirigida a Vicente Ripollés Pérez conservadas en su legado. Fuente: Elaboración propia a partir del legado VRP en VAcp.

inéditas se encuentra la relación epistolar que establecieron con él más de treinta músicos y musicólogos españoles, entre ellos los más interesantes de su época, como Felipe Pedrell e Higinio Anglés y también con otros compositores reformistas como Nemesio Otaño, Francisco Pérez Viñaspre, Luis Villalba, Lluís Romeu o Gregori Ma Sunyol. También se encuentra alguna de José Subirá y otras escritas por extranjeros como Henri Collet, musicólogo francés estudioso del Siglo de Oro de la música española, por Angelo de Santi, de la asociación italiana Santa Cecilia o por Wilhelm Merian, primer secretario de la Sociedad Internacional de Musicología entre 1927 y 1948.

Las fechas extremas referenciadas en los documentos epistolares son 1903 a 1936, aunque varios no aparecen fechados y algunos están rotos por la parte donde debía estar escrita la fecha al habérseles arrancado el sello. Cabe destacar que casi todas las cartas son manuscritos autógrafos y sólo algunas están escritas a máquina. Casi todas están escritas en castellano, excepto alguna en italiano, francés, alemán y latín y las escritas por Anglés que están en catalán. El recuento inicial de la correspondencia antes de su catalogación ofrece la cifra de 235 documentos y una docena más no dirigida a Ripollés. Entre la corres-

tas que Ripollés recibió de Pedrell y que publicó en el Boletín de la Sociedad Castellonense de Cultura. pondencia enviada a Ripollés encontramos unas 180 cartas y 44 tarjetas postales; véase Tabla 2.

Entre la correspondencia de Ripollés se encuentran 74 documentos que le dirigió Higinio Anglés (47 cartas y 27 tarjetas postales) entre 1919 y $1936 .{ }^{30}$ Todas las cartas se enviaron desde Barcelona, excepto tres desde Friburgo (28 de julio de

\footnotetext{
${ }^{30}$ Higinio Anglés (1888-1969) fue un eminente musicólogo catalán que tras ser ordenado sacerdote estudió en Barcelona y posteriormente en Freiburg, Göttingen y Múnich hasta que fue nombrado director del departamento de música de la Biblioteca de Catalunya en 1917. Posteriormente fue profesor de música en el Liceo de Barcelona (1927) y también en su Universidad (1933-36). Fue director desde su creación del Instituto Español de Musicología (1943), prelado de honor del papa y protonotario apostólico (1958) y decano del Pontificio Instituto de Música Sacra de Roma (1947-69), ciudad donde falleció. En 1958 el estado español le concedió la Gran Cruz de Isabel La Católica debido a que había llegado a ser una figura preeminente de la musicología internacional. Dedicó su vida a la investigación y escribió más de cien monografías, conferencias, comunicaciones, artículos y colaboraciones en libros, entre los que destacan sus estudios y ediciones musicales sobre los maestros C. de Morales, T. L. de Victoria, J. Pujol, J. Cabanilles y A. Cabezón, el Códice de las Huelgas, la música en Cataluña hasta el s. XIII, las cantigas de Santa María y la música en la corte de los Reyes Católicos. Jack Westrup, “Anglès, Higini [Anglés, Higinio]”, en The New Grove Dictionary of Music and Musicians, second revised edition,
} 
1923), Göttingen (28 de junio 1924) y Madrid (9 de agosto de 1927). Entre las cartas de Anglés hay alguna anotación del propio Pedrell (27.2.1919). Las tarjetas enviadas por Anglés fueron escritas desde Barcelona, excepto una desde Madrid (10 de noviembre de 1923) y otra desde Gandía (31 de diciembre de 1925). La relación epistolar entre estos dos musicólogos giró en torno a sus investigaciones en un tono de confianza mutua, en el que, por ejemplo, Anglés recomendaba a Ripollés que incluyera en el título de su libro sobre el villancico también el término cantata, o se quejaba del lamentable estado del archivo de Gandía del que había desaparecido ya algún documento que le había indicado Ripollés que viera.

Nemesio Otaño escribió a Ripollés unos 56 documentos (41 cartas y 15 tarjetas) desde 1908 a $1931 .{ }^{31}$ Entre esas cartas se encuentra una dirigida a Pedrell (26 de octubre de 1913), otra al P. [Mariano] Baixauli (19 de diciembre de 1920) y una de Carmelo Blay escrita desde Roma a Otaño (14 de septiembre de 1912). Casi toda la correspondencia que Otaño dirigió a Ripollés la escribió desde el Colegio de San Francisco Javier de Oña (Burgos) y del Seminario Pontificio de Comillas (Santander). Alguna desde Alzola (Guipúzcoa) (21 de julio de 1910), otras desde la Cueva de San Ignacio de Manresa (Barcelona) a finales de 1911 y desde los Colegios del Sagrado Corazón de Jesús de Palencia (28 de marzo de 1912) y Barcelona (4 de agosto de 1912). Muchas de estas cartas llevan el membrete de la revista Música Sacro-Hispana, de la que Otaño fue director y de Ecos musicales: revista bimestral de música.

El organista alavés Francisco Pérez de Viñaspre mantuvo una fluida correspondencia con Ripollés entre 1912 y 1931 a través de 21 cartas conservadas. ${ }^{32}$

29 vols., ed. Stanley Sadie y John Tirrell (Oxford y Nueva York: Oxford University Press, 2001), vol. 1, p. 1171.

${ }^{31}$ Nemesio Otaño (1880-1956) fue un compositor, organista y musicólogo vasco, una de las figuras esenciales en la reforma de la música sagrada en España durante la primera mitad del siglo XX. En 1896 ingresó en la Compañía de Jesús y pronto obtuvo el puesto de organista de la Basílica de Loyola. En 1907 organizó en Valladolid el primer Congreso Nacional de Música Sagrada, y ese mismo año fundó la revista Música Sacro-Hispana, que, siguiendo las propuestas del papa Pío X, sirvió para dar nuevos aires a la música religiosa que venía realizándose en España hasta el momento. Desde 1911 fue director del coro de la Universidad Pontificia de Comillas, que se convirtió en modelo de buen funcionamiento para otras agrupaciones corales religiosas de España. A partir de 1939 fue nombrado director del Conservatorio Superior de Música de Madrid, institución a la que aportó sus ideas pedagógicas renovadoras. Véase José López Calo, Nemesio Otaño: medio siglo de música religiosa en España (Madrid: ICCMU, 2010).

${ }^{32}$ Francisco Pérez de Viñaspre Ortiz (1854-1938) se formó en su localidad natal de Laguardia (Álava) y posteriormente en Vitoria. Obtuvo el puesto de organista en Elciego (Álava), en la colegiata de Logroño (1879) y en las catedrales de Zamora (1884), Vitoria (1886) y Burgos (1904). Desarrolló una gran actividad a favor de la reforma musical auspiciada por el Motu proprio del papa Pío X, en plena sintonía con el trabajo de otros de sus contemporáneos. Participó como ponente en los cuatro congresos de música sagrada y fue habitual colaborador de la
El vallisoletano Luis Villalba escribió una decena de cartas a Ripollés y probablemente las que le escribiera éste se hallen entre su legado que se conserva en el Convento de los $\mathrm{Pa}$ dres Filipinos Agustinos de su ciudad natal. ${ }^{33}$ En los legajos 4 y 5 se encuentran las cartas que le enviaron varias de las personalidades con las que mantuvo correspondencia entre 1898 y 1920, entre ellas Pedrell con el que intercambió unas 70 cartas. ${ }^{34}$

El maestro catalán Lluís Romeu le dirigió a Ripollés al menos 9 cartas entre 1921 y 1923 cuando había cambiado el magisterio de capilla de la catedral de Vic (Barcelona) por el puesto de organista debido a sus problemas de salud..$^{35}$

El propio Ripollés era consciente del interés y valor de su correspondencia y ya publicó en el Boletín de la Sociedad Castellonense de Cultura las cartas intercambiadas con Pedrell, uno de los maestros pioneros de la musicología española mejor considerado y que más influencia tuvo entre sus contemporáneos y en generaciones posteriores. ${ }^{36}$ Las numerosas cartas se publicaron durante los años 1922-1954, incluso tras el fallecimiento del propio Ripollés, que había enviado los originales al mencionado

revista Música Sacro-Hispana. Véase Sabin Salaberri et al., La Música en Álava (Vitoria: Fundación Caja Vital Kutxa, 1997).

${ }^{33}$ Luis Villalba (1872-1921) se formó en el Colegio de Padres Agustinos de su Valladolid natal; doctor en Filosofía y Letras, fue maestro de capilla en el Monasterio de San Lorenzo de El Escorial desde 1898 a 1916 y posteriormente organista de la iglesia de San Sebastián en Madrid. Como compositor escribió gran cantidad de música religiosa vinculada a la reforma del Motu proprio y desarrolló una intensa actividad como musicólogo, ya que escribió unos doscientos estudios fundamentalmente sobre la organografía española y biografías de sus contemporáneos. Fue director de varias revistas musicales de la época, como Biblioteca sacro-musical, Santa Cecilia y La ciudad de Dios. Por su labor a favor de la recuperación del pasado musical español fue nombrado académico de la Real Academia de Bellas Artes de San Fernando de Madrid y Guido Adler le escogió como miembro de la comisión para elaborar el Corpus Scriptorum de Musica. Elena Riera Climent, "Los manuscritos musicales de Luis Villalba Muñoz", en Actas del VIII Congreso sobre la Sociedad Española de Historia de las Ciencias y las Técnicas, coordinado por Luis Español, José Javier Escribano y $\mathrm{M}^{\mathrm{a}}$ Ángeles García (Logroño: Universidad de la Rioja, 2004), pp. 1003-1009.

${ }^{34} \mathrm{M}^{\mathrm{a}}$ Antonia Virgili, "Felipe Pedrell y el músico vallisoletano Luis Villalba: correspondencia inédita", Recerca Musicològica, 1 (1981), pp. 151-192.

${ }^{35}$ Lluís Romeu (1874-1937) era natural de Vic (Barcelona), de cuya catedral fue maestro de capilla entre 1901-1920. A partir de entonces desempeñó el cargo de organista en la misma debido a su delicada salud. Como compositor dejó más de trescientas obras y fue uno de los más interpretados en su época, destacando sus composiciones que impulsaron la renovación de la música religiosa con la vinculación del gregoriano y la música popular catalana. Como musicólogo destaca su ensayo sobre las melodías eclesiásticas y el canto popular y los Goigs del Roser que fue publicado en Materials. Obra del Cançoner Popular de Catalunya (Barcelona: Fundació Concepció Rabells i Cibils, 1928). Véase Miquel Saperas, "Mossén Lluís Romeu, apòstol de la música sagrada", Ausà, 76 (1973), pp. 169-186.

36 José López Calo, "Felip Pedrell y la reforma de la música religiosa”, Recerca Musicològica, 11-12 (1991-1992), pp. 157-209. 


\begin{tabular}{|c|c|c|c|c|}
\hline Persona & Destinatario & $\mathbf{N}^{0}$ cartas/tarjetas & Lugar escritura & Fechas \\
\hline Aguilar, José & $\begin{array}{l}\text { González Merchant, } \\
\text { Rafael }\end{array}$ & $1 \mathrm{c}$ & $\begin{array}{l}\text { Convento de Sto., Domingo } \\
\text { de Jerez de la Frontera } \\
\text { (Cádiz) }\end{array}$ & 2.XI.1908 \\
\hline Blay, Carmelo & Otaño, Nemesio & $1 \mathrm{c}$ & Roma & 14.IX.1912 \\
\hline Otaño, Nemesio & Breva, Manuel Andrés & $1 \mathrm{c} \mathrm{y} 1 \mathrm{t}$ & Comillas (Santander) & 13.IV.1917 y 2. VI.1917 \\
\hline Otaño, Nemesio & Pedrell, Felipe & $1 \mathrm{t}$ & [Oña (Burgos)] & 26.X.1913 \\
\hline Otaño, Nemesio & Baixauli, [Mariano] P. & $1 \mathrm{c}$ & Oña (Burgos) & 19.XII.1921 \\
\hline $\begin{array}{l}\text { Profesor del Seminario } \\
\text { de Valencia }\end{array}$ & $\dot{i}$ & $1 \mathrm{c}$ & [Valencia] & ¿ \\
\hline Sojo, Francisco C. & Roldán, Federico $^{1}$ & $1 \mathrm{c}$ & $\begin{array}{l}\text { Colegio de Vocaciones } \\
\text { Eclesiásticas del S. Corazón } \\
\text { y S. José de Plasencia } \\
\text { (Cáceres) }\end{array}$ & 26.X.1908 \\
\hline $\begin{array}{l}\text { Tebar Alemany, } \\
\text { Jerónimo }\end{array}$ & $\begin{array}{l}\text { Blanquer Copoví, Juan } \\
\text { (Valencia) }\end{array}$ & $1 \mathrm{c}$ & $\begin{array}{l}\text { Cartuja de Miraflores } \\
\text { (Burgos) }\end{array}$ & 18.IV.1942 \\
\hline Torres, Ignacio & Francisco Tito & $1 \mathrm{c}$ & Madrid & 19.IX.1922 \\
\hline Úbeda, José $M^{a}$ & Mariani, Luis [Sevilla] & $1 \mathrm{c}$ & Valencia & V.1903 \\
\hline $\begin{array}{l}\text { Vicario General de } \\
\text { Valencia }\end{array}$ & $\begin{array}{l}\text { Rector de Benigánim } \\
\text { (Valencia) }\end{array}$ & $1 \mathrm{c}$ & [Valencia] & $30 . I V \cdot i 1643 ?$ \\
\hline Villanueva, Modesto & $\begin{array}{l}\text { Manuel Villar } \\
\text { (Valencia) }\end{array}$ & $1 \mathrm{c}$ & $\begin{array}{l}\text { Cabezón de la Sal } \\
\text { (Santander) }\end{array}$ & 23.VII.1914 \\
\hline
\end{tabular}

Tabla 3. Correspondencia dirigida a otras personas conservada en el legado Vicente Ripollés Pérez. Fuente: elaboración propia a partir del legado VRP en VAcp.

${ }^{1}$ Carta redirigida a Vicente Ripollés para que se tuviera en cuenta la ponencia de F. Sojo en el congreso de Sevilla.

boletín en mayo de $1936 .{ }^{37}$ Estas cartas originales no se han localizado por lo que probablemente se quedaron en poder de quien las publicó en el Boletín, quizás Francisco Escoín Belenguer que realizó una semblanza sobre él. ${ }^{38}$

Aparte de esta nutrida correspondencia que Ripollés mantuvo con Pedrell y cuyos originales envió a la revista mencionada, éste conservó cinco cartas que le había escrito Pedrell

\footnotetext{
${ }^{37}$ Robres y Castell, "Las obras de D. Vicente Ripollés”, p. 136.

${ }^{38}$ Presbítero y organista en la iglesia de Santa María de Castellón desde 1912, poco conocido hasta el momento, Francisco Escoín Belenguer escribió obras pedagógicas, musicales e históricas como Apuntes biográfico-críticos para la historia del gran maestro y concertista de guitarra Tárrega (Castellón: Imp. J. Barberá, 1918); y Organografía musical castellonense (Castellón: Imp. J. Barberá, 1919). Fue académico correspondiente de la Real Academia de la Historia y un habitual colaborador del Boletín de la Sociedad Castellonense de Cultura, donde escribió artículos sobre la música en Castellón en el siglo XIX y una semblanza sobre Ripollés.
}

fechadas entre noviembre de 1903 y febrero de 1904 no mencionadas en su Fragmentos del epistolario de Pedrell (XIX). ${ }^{39}$

El resto de documentos, unos 40, revela una relación epistolar menos fluida con otros músicos menos conocidos y también implicados en la reforma de la música sacra, algunos de los cuales participaron en el congreso de música sagrada organizado por Ripollés en Sevilla en 1908. De ese año data una carta que le dirigió a Ripollés el valenciano Juan Bautista Guzmán desde su puesto como maestro en la Escolanía Montserrat, un año antes de su fallecimiento. Este maestro, pionero en la edición de las obras de Juan Bautista Comes, ${ }^{40}$ a su vez mantuvo

${ }^{39}$ Las cartas entre Ripollés y Pedrell publicadas en el Boletín de la Sociedad Castellonense de Cultura, así como otras conservadas en la Biblioteca de Catalunya, han sido comentadas en relación con la reforma ceciliana por Bombi, "En nombre del arte y de la Iglesia", pp. 169201.

40 Juan Bautista Guzmán, Obras musicales del insigne maestro español del siglo XVII Juan Bautista Comes, escogidas, puestas en partitura e ilustradas por Juan Bautista Guzmán (Madrid: Imprenta del Colegio Nacional de Sordomudos y de Ciegos, 1888). 
una relación epistolar interesante con los eminentes Barbieri y Pedrell. ${ }^{41}$

Curiosamente entre la correspondencia de Ripollés se encuentran 12 cartas y tarjetas escritas por varios músicos a otras personas; véase Tabla 3.

\subsection{Documentación profesional de carácter oficial}

Entre la documentación profesional de carácter oficial se encuentran los nombramientos de Ripollés en varios de los cargos que ocupó, por ejemplo, como presbítero en Tortosa, como maestro de capilla en la Catedral de Sevilla - firmado por el rey Alfonso XIII - , profesor del Conservatorio de Valencia, miembro de la Sociedad Internacional de Musicología o presidente de la Asociación Ceciliana Española que fue enviado desde Roma; véase Figura 8. También se conserva el reglamento de esta asociación y el programa de las oposiciones al magisterio de capilla de la Catedral de Valencia en 1727.

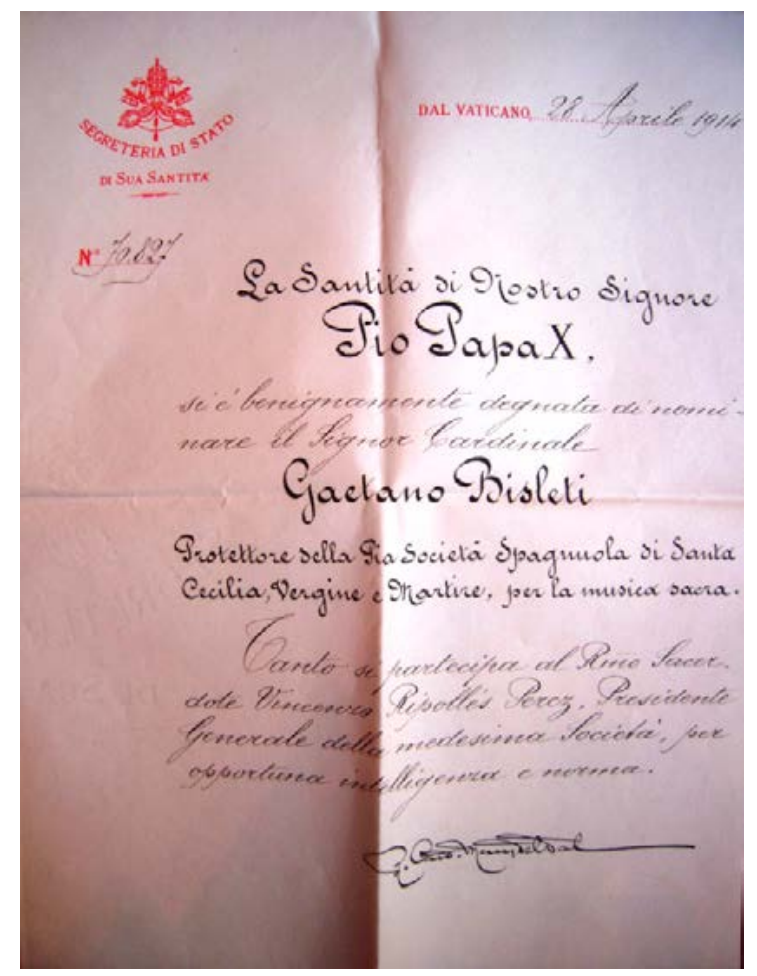

Figura 8. Designación de Ripollés como presidente de la Asociación Ceciliana Española. Roma, 1914. VAcp/Mus-VRP [Documentación sin catalogar].

${ }^{41}$ Francisco Bueno Camejo y José Salvador Blasco Magraner, Epístolas de la música religiosa española del s. XIX. La correspondencia entre Juan Bautista Guzmán, Francisco Asenjo Barbieri y Felipe Pedrell Sabaté (La Laguna: Sociedad Latina de Comunicación Social, 2013).

\subsection{Escritos autógrafos y documentación varia}

Se conserva gran cantidad de documentación generada durante el II Congreso Nacional de Música Sagrada que se celebró en Sevilla en 1908 y que estuvo organizado por Ripollés durante su magisterio en la catedral hispalense. Se encuentran las ponencias que expusieron los participantes y las anotaciones del propio Ripollés para la publicación de la memoria o crónica final.

Se conservan borradores autógrafos manuscritos de los estudios publicados por Ripollés sobre el villancico en Valencia y las epístolas farcides. ${ }^{42}$ Además, parecen de Ripollés los comentarios y escritura en un acta sobre Divini cultum del papa Pío XI con varias páginas sobre la constitución apostólica de promover cada día más la liturgia, el canto gregoriano y la música sagrada. Entre estos escritos se conservan unos Fragmentos del epistolario de Pedrell (núm. XIX) con 33 hojas autógrafas manuscritas.

También se encuentran otros manuscritos autógrafos que escribieron a finales del siglo XIX los maestros catedralicios y pioneros en la recuperación del patrimonio musical valenciano Juan Bautista Guzmán y Juan Bautista Pastor sobre la biografía de Juan Bautista Comes con una copia del testamento de este maestro del Barroco.

\section{CONCLUSIONES}

Tras esta visión global realizada por primera vez sobre el legado de Vicente Ripollés, es posible afirmar que resulta de enorme interés para el estudio de la música sacra española y europea, en una época de gran actividad musical y musicológica, que buscó inspiración en los maestros del pasado para renovar la música de su presente. Por ejemplo, este legado abre perspectivas para el estudio de la ideología y estética musical durante el cecilianismo, el grado de implantación de las directrices del Motu proprio y opiniones de los músicos al respecto, así como para profundizar en las técnicas de composición de la época. Entre las monografías y publicaciones periódicas de su biblioteca personal se encuentran ejemplares únicos, algunos de bastante antigüedad, poco difundidos o de difícil acceso en las bibliotecas.

Buena parte de las partituras compuestas por Ripollés que se conservan en su legado son ejemplares autógrafos y varios de ellos probablemente únicos. Hasta el momento se han publicado varios inventarios de la obra de Ripollés, realizados por Ruiz de Lihory, Robres, Climent, Bombi y López-Fernández. A pesar de que el último realizado es muy completo, ninguno recoge de forma conjunta la totalidad de sus escritos junto a sus composiciones, su localización e íncipit musical. Por tanto, sus obras

${ }^{42}$ Vicente Ripollés, El villancico $i$ la cantata del segle XVIII a València (Barcelona: Institut d'Estudis Catalans, Biblioteca de Catalunya, 1935) y "Epístola farcida de Navidad", Boletín de la Sociedad Castellonense de Cultura, 22 (1946), pp. 127-166. 
necesitan de un catálogo, que excede las limitaciones de este estudio, que permita cuantificar, localizar, valorar la dispersión y alcance de su producción. Una obra que hasta el momento permanece eclipsada por sus escritos musicológicos. Son necesarias también más ediciones que permitan interpretar, conocer y valorar su música.

Las partituras que pertenecieron a Ripollés, junto con las que legaron otros músicos de la época, como Enrique Domínguez Boví - también donadas al Real Colegio-, resultan de gran interés para el conocimiento del repertorio interpretado en los templos valencianos a finales del siglo XIX y comienzos del $\mathrm{XX}$. Estos legados personales se complementan con el repertorio generado en el transcurso de la actividad musical por las instituciones musicales.

Resulta de enorme interés la relación epistolar que mantuvo Ripollés con otros de sus renombrados contemporáneos, en especial la correspondencia que le enviaron Higinio Anglés, Nemesio Otaño, Francisco Pérez de Viñaspre, Luis Villalba, Lluís Romeu o Felipe Pedrell. El estudio de estas relaciones epistolares puede aportar una visión más amplia sobre las relaciones profesionales y personales, así como sobre la percepción de los protagonistas respecto al resultado de sus esfuerzos de reforma de la música sacra.

Sin duda, sería necesario un estudio en profundidad para conocer más sobre las redes de circulación de música, del comercio editorial, del entramado de relaciones entre los músicos religiosos más importantes de la época y la construcción ideológica en torno a la música en España y Centroeuropa durante el proceso de renovación de la música sacra católica entre los siglos XIX y XX.

Este epistolario entre músicos resulta ser uno de los pocos conservados en Valencia y solo superado en volumen por el de Eduardo López-Chávarri Marco conservado en la Biblioteca Valenciana entre su legado familiar. El epistolario del legado de Ripollés servirá no sólo para complementar la correspondencia que él escribió y que se conserva en otros lugares, sino para poner en valor su figura en el contexto de sus contemporáneos.

El legado de Vicente Ripollés Pérez conservado en el Real Colegio Seminario de Corpus Christi de Valencia resulta imprescindible para profundizar en el conocimiento de uno de los pioneros en la investigación musicológica en Valencia y en una de las figuras más importantes en la renovación de la música sacra en España entre los siglos XIX y XX.

\section{BIBLIOGRAFÍA CITADA}

Andrés Robres, Fernando. Inventario de los fondos notariales del Real Colegio Seminario de Corpus Christi. Valencia: Conselleria de Cultura, Educació i Ciència, 1990.

Benito Doménech, Fernando. Pinturas y pintores en el Real Colegio de Corpus Christi. Valencia: Federico Doménech S.A., 1980.

Benito Goërlich, Daniel. "San Juan de Ribera, mecenas del arte". Studia philologica valentina, 15 (2013), pp. 49-86.
—_. "El legado Elías Tormo en el Real Colegio y Seminario de Corpus Christi de Valencia". En Elías Tormo, apóstol de la historia del arte en España, dirigido por L. Arciniega. Valencia: Institució Alfons El Magnànim, 2016, pp. 329-330.

Biblioteca Valenciana. Catálogo Colectivo del Patrimonio Bibliográfico. Música. Real Colegio Seminario de Corpus Christi. <http://bv.gva.es/cginetbv-bin/abnopacbvccp/ O6405/IDfaf84e13/NT1> [consultado el 16 de julio de 2019].

Bombi, Andrea. "Ripollés Pérez, Vicente". En Diccionario de la música valenciana, 2 vols., dirigido por Emilio Casares. Madrid: Iberautor Promociones Culturales, 2006, vol. 2, pp. 344-346.

Bombi, Andrea. "En nombre del arte y de la Iglesia: Vicente Ripollés y la reforma ceciliana". En Pasados presentes. Tradiciones historiográficas en la musicología europea (1830-1930), editado por A. Bombi. Valencia: Universitat de València, 2015, pp. 169-201.

Bueno Camejo, Francisco Carlos y José Salvador Blasco Magraner. Epístolas de la música religiosa española del s. XIX. La correspondencia entre Juan Bautista Guzmán, Francisco Asenjo Barbieri y Felipe Pedrell Sabaté. Cuadernos de Bellas Artes, 25. La Laguna: Sociedad Latina de Comunicación Social, 2013.

Casares, Emilio. Francisco Asenjo Barbieri. Documentos sobre música española y epistolario (Legado Barbieri), 2 vols. Madrid: Fundación Banco Exterior, 1988.

Castro Martínez, Elena, Ignacio Fernández de Lucio y Felipe Criado. "La transferencia del conocimiento desde las $\mathrm{Hu}$ manidades: posibilidades y características". Arbor. Ciencia, Pensamiento y Cultura, 732 (2008), pp. 619-636.

Climent, José. "Ripollés Pérez, Vicente". En Gran Enciclopedia de la Región Valenciana. Valencia: M. García Cantos, 1973 , p. 56.

- Historia de la música contemporánea valenciana. Valencia: Del Cénia al Segura, 1978.

- Fondos musicales de la Región Valenciana. II. Real Colegio - Seminario de Corpus Christi. Valencia: Institución Alfonso el Magnánimo, 1984.

Díaz Gómez, Rafael y Vicente Galbis López. Eduardo López-Chavarri Marco: correspondencia. Valencia: Generalitat Valenciana, 1996.

Escoín Belenguer, Francisco. "El maestro D. Vicente Ripollés, canónigo de la Catedral de Valencia. Evocaciones músico-sacras". Boletín de la Sociedad Castellonense de Cultura (1949), pp. 580-584.

Ferrer Granell, Vicente: [Inventario de las] Cartas y papeles oficiales de D. Vicente Ripollés. Valencia, 2008. Inédito.

Guzmán, Juan Bautista. Obras musicales del insigne maestro español del siglo XVII Juan Bautista Comes, escogidas, puestas en partitura e ilustradas por Juan Bautista Guzmán. Madrid: Imprenta del Colegio Nacional de Sordomudos y de Ciegos, 1888. 
Isusi-Fagoaga, Rosa y Greta Olson. "Hacia un catálogo colectivo del patrimonio musical valenciano: el Real Colegio Seminario de Corpus Christi como primer paso". Boletín DM (Asociación Española de Documentación Musical, AEDOM), 11 (2007), pp. 92-97.

Isusi-Fagoaga, Rosa. "El cantante Enrique Domínguez Boví, el teatro lírico y su colaboración con Manuel de Falla". En Delantera de Paraíso. Estudios en homenaje a Luis G. Iberni, editado por Celsa Alonso, Carmen Julia Gutiérrez y Javier Suárez-Pajares. Madrid: ICCMU, 2009, pp. 187199.

. "El gremio musical en Valencia entre los siglos XIX y $\mathrm{XX}$ y el legado Enrique Domínguez Boví”. Cuadernos de música iberoamericana, 22 (2011), pp. 99-122.

- "La edición y recepción de música sacra en Valencia (ss. XVIII-XX): fuentes y publicaciones periódicas". En Imprenta y edición musical en España (siglos XVIII-XX), editado por Begoña Lolo y José Carlos Gosálvez. Madrid: Universidad Autónoma de Madrid, Ministerio de Economía y Competitividad, 2012, pp. 365-380.

- Sevilla y la música de Pedro Rabassa. Los sonidos de la catedral y su contexto urbano en el s. XVIII, 3 vols. Sevilla: Junta de Andalucía. Consejería de Cultura y Deporte, 2012.

—. "La Música del Real Colegio Seminario de Corpus Christi (Patriarca): Primera visión global a la luz de su catalogación informática". Real Academia de Bellas Artes de San Carlos Valencia. Anuario (2014), pp. 43-56.

López Calo, José. "Felip Pedrell y la reforma de la música religiosa”. Recerca Musicològica, 11-12 (1991-1992), pp. 157-209.

- Nemesio Otaño: medio siglo de música religiosa en España. Madrid: ICCMU, 2010.

López-Fernández, Miguel. La aplicación del Motu proprio sobre música sagrada de Pío X en la archidiócesis de Sevilla (1903-1910): gestión institucional y conflictos identitarios. Tesis doctoral. Granada: Universidad de Granada, 2014.

López-Fernández, Miguel, ed. Vicente Ripollés Pérez (18671943). Música en torno al Motu proprio para la catedral de Sevilla. Vol. 1. Misas. Estudio y edición. Monumentos de la Música Española, 83. Madrid: Consejo Superior de Investigaciones Científicas. Editorial CSIC; Barcelona: Institución Milá y Fontanals, 2017.

Martínez Tórtola, M. “Un Colegio junto al Estudio General. El Real Colegio de Corpus Christi y la Universitat de València”. En Domus Speciosa. 400 años del Colegio del Patriarca. Valencia: Universitat de València, 2006, pp. 265284.

Medina Álvarez, Ángel. "La música en el templo tras el motu proprio de San Pío X: una mirada desde los archivos de la Iglesia”. Memoria ecclesiae, 31 (2008), pp. 21-44. Ejemplar dedicado a: Música y archivos de la iglesia. Santoral hispano-mozárabe en las Diócesis de España. Actas del
XXI Congreso de la Asociación celebrado en Santander, 12 al 16 de septiembre de 2005.

Micó Terol, Elena. Amancio Amorós Sirvent (1854-1925) y su proyección en la vida musical valenciana. Tesis doctoral. Barcelona: Universitat de Barcelona, 2012. <http://diposit. ub.edu/dspace/handle/2445/35621>.

Olson, Greta. “Armonía sacra y solemne. La capilla musical del Colegio de Corpus Christi y su archivo". En Domus Speciosa. 400 años del Colegio del Patriarca. Valencia: Universitat de València, 2006, pp. 245-264.

Olson, Greta y Rosa Isusi-Fagoaga. "The Music Archive and Library at the Real Colegio Seminario de Corpus Christi (Valencia)". Fontes Artis Musicae, 55/3 (2008), pp. 512518.

Oriola Velló, Frederic. Temps de músics i capellans: l'influx del motu proprio Tra le sollicitudini a la diòcesi de València (1903-1936). Valencia: Federació de Societats Musicals de la Comunitat Valenciana, 2011.

Picó Pascual, Miguel Ángel. "La aportación musicológica del canónigo Vicente Ripollés Pérez”. Revista de Musicología, 27/1 (2004), pp. 287-292.

Riera Climent, Elena. "Los manuscritos musicales de Luis Villalba Muñoz". En Actas del VIII congreso sobre la Sociedad Española de Historia de las Ciencias y las Técnicas, coordinado por Luis Español, José Javier Escribano y $\mathbf{M}^{\mathrm{a}}$ Ángeles García. Logroño: Universidad de la Rioja, 2004, pp. 1003-1009.

[Ripollés Pérez, Vicente]. Crónica del segundo congreso nacional de música sagrada celebrado en Sevilla los días 12, 13, 14 y 15 de noviembre de 1908. Sevilla: Izquierdo y Comp $^{\mathrm{a}}$, [1909].

Ripollés Pérez, Vicente. Memoria sobre la reforma de la música religiosa en la Capilla del Real Colegio de Corpus Christi de Valencia. Madrid: Imp. y Lit. de la Viuda e Hijos de Terceño, 1897.

_. "Fragmentos del epistolario de Pedrell". Boletín de la Sociedad Castellonense de Cultura, 3-30 (1922-1954).

- El villancico $i$ la cantata del segle XVIII a València. Barcelona: Institut d'Estudis Catalans, Biblioteca de Catalunya, 1935.

_. "Epístola farcida de Navidad". Boletín de la Sociedad Castellonense de Cultura, 22 (1946), pp. 127-166.

Robres, Ramón y Vicente Castell. "Las obras de D. Vicente Ripollés Pérez, Presbítero". Boletín de la Sociedad Castellonense de Cultura, 19/2 (1944), pp. 132-138.

Robres, Ramón. San Juan de Ribera, patriarca de Antioquía, arzobispo, virrey y capitán general de Valencia, 15321611: humanismo y eclosión mística. Valencia: Edicep C.B., 2002.

Royo Conesa, Mireya. La Capilla del Colegio del Patriarca: Vida musical y pervivencia de las danzas del Corpus de Juan Bautista Comes (1603-1706). Tesis doctoral. Oviedo: Universidad de Oviedo, 2016.

Ruiz de Lihory, José. "Ripollés (Vicente)". La música en Valencia. Diccionario biográfico y crítico. Valencia: Domé- 
nech, 1903; edición facsímil, Valencia: Librerías París-Valencia, 1987, pp. 388-389.

Salaberri, Sabin et al. La Música en Álava. Vitoria: Fundación Caja Vital Kutxa, 1997.

Saperas, Miquel. "Mossén Lluís Romeu, apòstol de la música sagrada”. Ausà, 76 (1973), pp. 169-186.

Virgili, Ma Antonia. "Felipe Pedrell y el músico vallisoletano Luis Villalba: correspondencia inédita". Recerca Musicològica, 1 (1981), pp. 151-192.

- "La música religiosa en el s. XIX español". Revista Catalana de Musicologia, 2 (2004), pp. 181-202.

- "Antecedentes y contexto ideológico de la recepción del Motu Proprio en España". En Actas del Simposio In- ternacional 'El Motu Proprio de San Pío X y la música (1903-2003)' (Barcelona, 26-28 de noviembre de 2003). Revista de Musicología, 27/1 (2004), pp. 23-42.

Westrupt, Jack. "Anglès, Higini [Anglés, Higinio]". En The New Grove Dictionary of Music and Musicians, second revised edition, 29 vols., editado por Stanley Sadie and John Tirrell. Oxford y Nueva York: Oxford University Press, 2001, vol.1, p. 1171.

Recibido: 16.07.2019

Aceptado: 16.08.2019 